\title{
EDITORIAL
}

\section{Germinou e nasceu!}

Com grande entusiasmo e satisfação, apresentamos ao leitor o primeiro número da Revista Voluntas: Estudos sobre Schopenhauer. Fundado no ano em que rememoramos os 150 anos da morte do pensador, eis o primeiro periódico brasileiro que se propõe a divulgar pesquisas exclusivamente sobre o pensamento do filósofo alemão, tais como suas fontes e suas influências em outros pensamentos.

A ideia de organizarmos uma revista que publicasse estudos especializados sobre a filosofia de Schopenhauer surgiu no final do ano de 2009 e foi sugerida por Renato Nunes Bittencourt, então doutorando (e hoje doutor) em Filosofia pela Universidade Federal do Rio de Janeiro, e aderida por outros dois doutorandos em Filosofia pela Universidade de São Paulo, Vilmar Debona e Diana Chao Decock. Durante o primeiro semestre de 2010, esse mesmo grupo, que inicia compondo o quadro dos Editores do periódico, tomou as primeiras providências para que a ideia da revista se efetivasse; convidou para a composição do Conselho Editorial os mais renomados pesquisadores de Schopenhauer das universidades brasileiras, tais como UNICAMP, PUC-Rio, USP, PUCPR e UFPB, e também do exterior, tal como da Johannes-Gutenberg Universität Mainz (Alemanha), da Università del Salento (Itália), da University of Southampton (Inglaterra) e da Kwansei Gakuin University (Japão), além de membros da Schopenhauer Gesellschaft, da Alemanha, e do Centro interdipartimentale di ricerca su Schopenhauer e la sua scuola, de Lecce, Itália.

Com o apoio de mais de vinte professores do Brasil e de países onde a Schopenhauer-Forschung já está consolidada há muito tempo, a Revista Voluntas começou a ser divulgada e conhecida mesmo antes de sua primeira edição: durante o Encontro Para saber mais Schopenhauer IV, realizado na Universidade Estadual de Campinas, de 31 de agosto a 2 de setembro deste ano, a ideia do periódico foi disseminada, e na Reunião do GT 
[Grupo de Trabalho] Schopenhauer de 2010, ocorrida durante o XIV Encontro de Pós-Graduação em Filosofia do Brasil, em Águas de Lindóia, São Paulo, foi até mesmo cogitada a possibilidade de a revista vir a se tornar, no Brasil, o órgão oficial de divulgação da pesquisa Schopenhauer, incorporando-a ao próprio GT. Passados poucos dias das divulgações mencionadas acima, tivemos a grata oportunidade de recebermos cerca de vinte submissões de artigos para publicação. Diante de tamanha colaboração de professores doutores, mestres e pós-graduandos, decidimos iniciar oficialmente os trabalhos com a revista publicando duas edições ainda este ano. Assim, o presente número refere-se ao primeiro semestre de 2010, e o segundo número, que será lançado durante o mês de dezembro, referir-se-á ao segundo semestre deste ano.

Além da mencionada proximidade com o GT Schopenhauer da ANPOF, a Revista Voluntas é inaugurada como periódico vinculado aos Programas de Pós-Graduação em Filosofia da Universidade de São Paulo (USP), da Universidade Federal do Rio de Janeiro e da Pontifícia Universidade Católica do Paraná (PUCPR). Trata-se, pois, de uma revista nacional, mas com uma significativa projeção internacional, já que, além da presença de professores pesquisadores de universidades estrangeiras, propõe-se a publicar artigos nos idiomas inglês, espanhol, italiano, francês e alemão, conforme explicitado nas Normas para publicação.

Não somente por se tratar do "nascimento" da revista, mas também pelas determinantes contribuições dos autores que enviaram artigos e pelo apoio dos professores membros do Conselho Editorial, estamos suficientemente motivados para inaugurarmos este novo veículo de divulgação do fecundo pensamento schopenhaueriano com boas expectativas. Quando recordamos os grandes leitores de Schopenhauer no Brasil, talvez não lembremos de outros nomes senão os de Machado de Assis e de Augusto dos Anjos, e, em nossa vizinha Argentina, do eminente Jorge Luis Borges. Por outro lado, talvez possamos afirmar que esta recepção no sul das Américas, embora tenha sido reticente -com exceção dos últimos quinze anos -possa ser instigada pela ocasião do lançamento da Revista Voluntas. E, quiçá, esta iniciativa seja uma forma de efetivação do que afirmara Schopenhauer na ocasião de sua fuga de Berlim a Rudolstadt, em maio de 1813, por não querer servir nas batalhas contra os franceses: “[...] estava profundamente convencido de que não tinha nascido para servir à humanidade mediante os punhos, mas pela cabeça, e de 
que a minha pátria era maior que a Alemanha". Se a recepção da filosofia schopenhaueriana se deu com reticências e tardiamente no Brasil, acreditamos que a Revista Voluntas seja uma forma de disseminar esta visão de mundo tão cara ao século XX.

A Revista Voluntas possui edições temáticas, mas também publica - em um mesmo número -artigos em fluxo contínuo, assim como uma Seção de Resenhas. Por isso, o presente número apresenta: a) três artigos sobre a temática "Schopenhauer: liberdade e razão", b) cinco estudos no fluxo contínuo e c) duas resenhas.

Uma das questões nevrálgicas da filosofia de Schopenhauer é o debate em torno da liberdade. A envergadura deste tema se mostra, por exemplo, quando consideramos que 1) expõe o núcleo da Weltanschauung do pensador alemão, na medida em que é consoante ao crucial conceito de Vontade; 2) remete-nos ao conceito de negação da vontade que, ao espelhar o pessimismo tão característico desta filosofia, conduz a uma forma peculiar de liberdade, tida como sua única possibilidade no mundo fenomênico; e 3) filia Schopenhauer ao debate de outros grandes filósofos da história da Filosofia, caso explícito de seu mestre Kant. Além disso, ao propormos a temática "liberdade e razão" podemos pensar, concomitantemente, na essência volitiva do mundo que, segundo Schopenhauer, é livre, e, justamente por isso, contribui com o questionamento e com a despotencialização das pretensões da razão quando se pretende dizer o sentido do mundo. Em verdade, seria pela pauta da questão da liberdade na terceira antinomia da Crítica da razão pura que o "autêntico discípulo" daquele cuja cabeça seria a "mais original" que a natureza jamais produziu (o próprio Kant) reconheceria nesta discussão o estágio mais alto da filosofia kantiana; e, também, que afirmaria: "Este é o ponto [o da liberdade] em que a filosofia de Kant conduz à minha, ou em que esta brota daquela como um galho do tronco" (Cf. Crítica da filosofia kantiana, Apêndice a $O$ mundo como vontade e como representação, Trad. Jair Barboza, São Paulo, Edusp, 2005, p. 624). Ora, sobre esta temática, apresentamos os artigos da doutoranda Selma Bassoli, intitulado A negação da Vontade e o ponto de ebulição da água, onde a autora argumenta acerca da supressão do princípio de individuação através da prática ascética tal como descrita por Schopenhauer no IV livro de 
O mundo como vontade e como representação; o texto do doutorando Fabiano Queiroz da Silva, intitulado De Kant a Schopenhauer: análise da Terceira Antinomia da Razão Pura e de sua solução, onde temos uma reconstrução da terceira antinomia da Crítica da razão pura, de Kant, tal como da solução crítica dada a ela pelo pensador, e também uma investigação do embate entre Kant e Schopenhauer quanto a esta mesma solução; e também o estudo da mestranda Gleisy Picoli, denominado Poder versus querer: Sobre o livre-arbitrio em Agostinho e em Schopenhauer, que analisa uma crucial distinção entre a perspectiva moralista da noção cristã de livre-arbítrio e a crítica schopenhaueriana a tal concepção, ainda que esta seja notadamente influenciada pela tese agostiniana.

Na seção Fluxo contínuo, contamos com a colaboração do professor Dr. Renato Nunes Bittencourt, com o texto Justiça, caridade e compaixão na Metafísica da Ética de Schopenhauer, que apresenta a compreensão schopenhaueriana acerca do fundamento metafísico da moral, decorrente da compreensão da unidade ontológica entre todos os seres vivos, em contraponto ao formalismo da ética kantiana; um artigo em língua italiana do professor Dr. Fabio Ciracì, da Università del Salento (Lecce, Itália), intitulado Il mondo come volontà, idee e rappresentazione: per una possibile lettura in senso illuministico della dottrina delle idee, que apresenta uma detalhada reflexão sobre por que Schopenhauer tomou como recurso em sua filosofia a doutrina das ideias, como foi o desenvolvimento de tal doutrina no âmbito de seu sistema metafísico, além de esclarecer quais elementos teoréticos a compõem e qual é a principal função dessa Ideenlehre; um trabalho de Luan Corrêa da Silva, denominado Ilustrações para uma metafísica da música a partir de Schopenhauer, que aborda a importância da arte musical na metafísica do belo em Schopenhauer, arte esta que expressa a própria Vontade e não as Idéias, tal como as demais belas artes; um estudo do mestrando Felipe Durante sob o título de Um tipo de justiça infalivel: A Justiça Eterna, onde o autor analisa a concepção schopenhaueriana da base metafísica da justiça, na qual se postula tese de que o mal cometido contra outrem em verdade afeta o próprio agressor, pois a distinção entre os seres se dá apenas no âmbito fenomênico e não na esfera da Vontade, que, sendo una, constitui todos os seres; e, por fim, um estudo do professor Dr. Tristan Torriani, da Universidade Estadual de Campinas (Unicamp) intitulado Schopenhauer, Wagner e a Ópera: algumas dificuldades com a metafísica musical a partir de uma abordagem psicolingüística, que, além de debater as 
noções de pensamento e de linguagem paralelamente à concepção schopenhaueriana de música, discute a apropriação por Wagner da noção de ópera, tal como formulada por Schopenhauer.

Na seção Resenhas, apresentamos o estudo crítico e detalhado dos mestrandos Glauber Klein e Élcio dos Santos sobre o livro Schopenhauer e as formas da razão: o teórico, o prático e o ético-místico (Annablume, 2010), de Vilmar Debona; assim como a análise do mestre Marcelo Santos do livro Metafísica do sofrimento do mundo: o pensamento filosófico pessimista (Ideia, 2009), de Deyve Redyson.$$
* * *
$$

Com votos de êxitos nas pesquisas Schopenhauer e para a Revista Voluntas, agradecemos aos colaboradores que enviaram seus artigos para este primeiro número e desejamos a todos uma excelente leitura.
\end{abstract}

Os Editores 